\title{
Anti-Ro(SSA) positive rheumatoid arthritis (RA): a clinicoserological group of patients with high incidence of D-penicillamine side effects
}

\author{
HARALAMPOS M MOUTSOPOULOS, ${ }^{1}$ FOTINI N SKOPOULI, \\ ARISTIDIS K SARRAS, ${ }^{1}$ CONSTANTINOS TSAMPOULAS, ${ }^{2}$ \\ ANESTIS K MAVRIDIS, ${ }^{3}$ STAVROS H CONSTANTOPOULOS, ${ }^{1}$ AND \\ PETER J MADDISON
}

From the Departments of ${ }^{1}$ Medicine, ${ }^{2}$ Radiology, ${ }^{3}$ Microbiology, Medical School, University of Ioannina, Ioannina, Greece, and the ${ }^{4}$ Royal National Hospital for Rheumatic Diseases, Bath, England

SUMMARY The clinical, laboratory, histological, and radiological manifestations of 90 Greek patients with anti-Ro(SSA) negative rheumatoid arthritis (RA) were compared with those of 15 Greek patients with anti-Ro(SSA) positive RA. Anti-Ro(SSA) positive RA patients had the same articular and extra-articular manifestations as anti-Ro(SSA) negative patients. However, they were predominantly females with lower rheumatoid factor titres and a high incidence of positive minor salivary gland biopsy specimens for Sjögren's syndrome. Finally, anti-Ro(SSA) positive RA patients frequently experienced penicillamine side effects.

Key words: Sjögren's syndrome, antibodies to Ro(SSA).

Antibodies to the soluble ribonucleoprotein $(\operatorname{Ro}(\mathrm{SSA}))^{1}$ extractable cellular antigen occur predominantly in patients with primary Sjögren's syndrome $(\mathrm{SS})^{2-4}$ and systemic lupus erythematosus (SLE) ${ }^{5}$ particularly in seronegative lupus, ${ }^{6}$ subacute lupus, ${ }^{7}$ and lupus patients with histological manifestations of SS. ${ }^{8}$ This antibody has also been described in rheumatoid arthritis (RA) patients with sicca syndrome ${ }^{9}$ and in some patients with systemic sclerosis. ${ }^{10}$ In a recent Greek study this antibody occurred in $25 \%$ of SLE patients, in approximately $10 \%$ of scleroderma patients, in $40 \%$ of SS patients, and in $15 \%$ of RA patients. A major feature was that anti-Ro positive RA patients experienced a high frequency of D-penicillamine side effects. ${ }^{11}$

In this study we compare the clinical, laboratory, histological, and radiological manifestations of antiRo(SSA) positive RA patients with those of antiRo(SSA) negative RA patients and examine the response of the two groups to penicillamine treatment.

Accepted for publication 2 November 1984.

Correspondence to $\mathrm{Dr} \mathrm{H}$ M Moutsopoulos. Department of Medicine, Medical School. University of Ioannina, 45332 Ioannina. Greece.
We confirm that anti-Ro(SSA) positive RA patients constitute a subgroup of RA patients with different serological and histological manifestations and a high incidence of D-penicillamine side effects.

\section{Materials and methods}

Sera of 105 consecutive unselected patients with definite or classical $\mathrm{RA}^{12}$ who were diagnosed and followed up in our clinic were examined by double immunodiffusion and counterimmunoelectrophoresis techniques for antibodies to Ro(SSA) cellular antigen as previously described. ${ }^{13}$ Antibodies were detected in 15 patients who composed the anti-Ro(SSA) positive group. The remaining 90 patients constituted the anti-Ro(SSA) negative group.

From the medical records the age, sex, disease duration, articular (arthritis of small and large joints) and extra-articular manifestations (rheumatoid nodules, splenomegaly, lymphadenopathy, pleurisy, xerophthalmia, xerostomia, and vasculitis) were recorded and compared in the two groups (Tables 1 and 2). The admission rheumatoid factor (RF) titres, serum C-reactive protein (CRP) levels, erythrocyte 
Table 1 Biographical information

\begin{tabular}{|c|c|c|}
\hline & Anti-Ro(SSA) negative & Anti-Ro(SSA) positive \\
\hline Number of patients & 90 & 15 \\
\hline Male/female & $22 / 78$ & $1 / 14$ \\
\hline Age (years) & $53 \cdot 6 \pm 13 \cdot 8^{*}$ & $49 \cdot 2 \pm 9 \cdot 7$ \\
\hline Disease duration (years) & $8 \cdot 4 \pm 10 \cdot 4$ & $8 \cdot 3 \pm 6 \cdot 6$ \\
\hline Follow up (years) & $1 \cdot 1 \pm 0 \cdot 6$ & $1 \cdot 2 \pm 0 \cdot 5$ \\
\hline
\end{tabular}

Table 2 Clinical diseases of the two groups of patients

\begin{tabular}{|c|c|c|}
\hline Manifestations & $\begin{array}{l}\text { Anti-Ro(SSA) negative } \\
(\% \text { with disease })\end{array}$ & $\begin{array}{l}\text { Anti-Ro(SSA) positive } \\
\text { (\% with disease) }\end{array}$ \\
\hline Arthritis (small joints) & $24 \cdot 4$ & 20 \\
\hline (small and large joints) & $75 \cdot 5$ & 80 \\
\hline Subcutaneous nodules & 10 & $6 \cdot 6$ \\
\hline Pleurisy & $7 \cdot 7$ & $13 \cdot 3$ \\
\hline Splenomegaly & $3 \cdot 3$ & $6 \cdot 6$ \\
\hline Lymphadenopathy & $18 \cdot 8$ & 20 \\
\hline Interstitial lung disease & 29 & 22 \\
\hline Vasculitis & $3 \cdot 3$ & 0 \\
\hline Xerophthalmia & $16 \cdot 6$ & $26 \cdot 6$ \\
\hline Xerostomia & 20 & 20 \\
\hline Lip biopsy specimens (lymphoid infiltrates) & $9 \cdot 5$ & $53 \cdot 8^{*}$ \\
\hline
\end{tabular}

${ }^{*} \chi^{2}=12 \cdot 18, \mathrm{p}<0 \cdot 005$.

Table 3 Laboratory results in the two groups

\begin{tabular}{lcc}
\hline & Anti-Ro(SSA) negative & Anti-Ro(SSA) positive \\
\hline Anaemia (\% with disease) & $8 \cdot 8$ & $20 \cdot 0$ \\
Leucopenia (\% with disease) & $3 \cdot 3$ & $6 \cdot 6$ \\
CRP (mg/l) & $42 \cdot 3 \pm 40 \cdot 4^{*}$ & $35 \cdot 8 \pm 48 \cdot 3$ \\
RF (titre) & $132 \cdot 6 \pm 296 \cdot 3$ & $43 \cdot 3 \pm 44 \cdot 3+$ \\
\hline
\end{tabular}

${ }^{*}$ Mean \pm standard deviation. ${ }^{*}$

$\dagger t=2.62, \mathrm{p}<0.01$.

sedimentation rate, anaemia $(\mathrm{Hb}<9 \mathrm{~g} / \mathrm{dl})$, leucopenia (leucocytes $<4 \times 10^{9} / \mathrm{l}$ ), and thrombocytopenia (platelets $<100 \times 10^{9} / 1$ ) were also analysed (Table 3 ). Finally, effectiveness and side effects of penicillamine treatment were recorded (Table 4).

Seventeen anti-Ro negative RA patients and nine anti-Ro positive RA patients were evaluated for interstitial lung disease with a respiratory questionnaire,$^{14}$ physical examination, chest roentgenogram, spirometry, and arterial blood gas analysis. We considered the presence of positive findings in at least two of the three parameters: clinical, roentgenological, and functional, to be evidence of diffuse interstitial lung disease.

The hand $x$-rays of 30 anti-Ro(SSA) negative and
anti-Ro(SSA) positive RA patients were reviewed without knowledge of other clinical or serological $N$ features using the grading system proposed by Larsen (Table 5). ${ }^{15}$ The presence of at least one $N$ lesion of a particular grade at any location on either $\omega$ hand was used for grading.

Labial minor salivary glands were biopsied ran- $C$ domly on 42 anti-Ro(SSA) negative RA patients and 13 anti-Ro(SSA) positive patients. Haematoxy-? lin and eosin stained slides were blindly read and graded according to Tarpley's classification. ${ }^{16}$ Only biopsy specimens with infiltrates greater than $2+$ were considered positive.

For statistical analysis the $\chi^{2}$ test and Student's $t$ test were used. 
Table 4 Penicillamine treatment: effectiveness and side effects

\begin{tabular}{llc}
\hline & Anti-Ro(SSA) negative & Anti-Ro(SSA) positive \\
\hline Number of patients & 47 & 13 \\
Side effects (no. of patients) & 4 & $8^{*}$
\end{tabular}

${ }^{*} \chi^{2}=13.97, p<0.005$.

Table 5 Grading of the radiological lesion in the hand $\mathrm{x}$-rays in the two groups

\begin{tabular}{lll}
\hline & Anti-Ro(SSA) negative & Anti-Ro(SSA) positive \\
\hline $\begin{array}{l}\text { Number of patients } \\
\text { Erosions }\end{array} \quad 21$ & 9 \\
$\quad<$ grade 3 & 11 & 1 \\
$>$ grade 3 & 10 & $8^{*}$ \\
\hline
\end{tabular}

${ }^{*}$ Not statistically significant.

\section{Results}

The male to female ratio, the mean age, the disease duration, and duration of follow up of the two groups of patients are given in Table 1 . The only difference was that anti-Ro(SSA) positive RA patients were predominantly females, while antiRo(SSA) negative RA affected males to females in a $1: 3$ ratio.

The incidence of articular and extra-articular manifestations and the histological changes in the minor salivary glands of the two groups of patients are given in Table 2 . The pattern of arthritis and the incidence of extra-articular manifestations were similar, while anti-Ro(SSA) positive RA patients more often had lymphoid infiltrates in the labial salivary gland biopsy specimens compared with the anti-Ro(SSA) negative group.

The only laboratory parameter which differed significantly (Table 3 ) was the serum rheumatoid factor titre $(t=2 \cdot 62, \mathrm{p}<0.01)$ which was lower in the anti-Ro(SSA) positive group. The severity of the radiological erosions tended to be greater in the anti-Ro(SSA) positive group, though this difference did not reach statistical significance (Table 5).

Forty-seven anti-Ro(SSA) negative RA patients and 13 anti-Ro(SSA) positive RA patients were treated with D-penicillamine for more than six months (mean duration follow up was 13.8 months). The D-penicillamine dose did not exceed $500 \mathrm{mg}$ daily. Eight of the 13 anti-Ro(SSA) positive RA patients developed side effects within six months of treatment, consisting primarily of skin rashes, decreased taste sensation, fever, leucopenia, and proteinuria. In contrast $4 / 47$ anti-Ro(SSA) negative RA patients developed side effects. One of these patients developed proteinuria, another myasthenia gravis, and two patients had loss of taste sensation (Table 4). Table 6 shows the side effects in the Ro(SSA) positive group in more detail.

Table 6 Penicillamine side effects in the $R o(S S A)$ positive $R A$ patients

\begin{tabular}{lllllll}
\hline Patient & Sex & Age & $\begin{array}{l}\text { Duration of disease } \\
\text { before treatment } \\
\text { (years) }\end{array}$ & $\begin{array}{l}\text { Duration of } \\
\text { treatment } \\
\text { (months) }\end{array}$ & Effectiveness & Side effects \\
\hline 1 & Male & 50 & 6 & 5 & + & Mouth ulcers rash \\
2 & Female & 62 & 5 & $1 \cdot 5$ & + & Fever \\
3 & Female & 54 & 2 & 4 & + & Butterfly rash \\
4 & Female & 60 & 15 & 1 & + & Decreased taste sensation \\
5 & Female & 46 & $1 \cdot 5$ & 6 & + & Transient skin rash \\
6 & Female & 46 & 4 & 4 & + & Proteinuria, skin rash \\
7 & Female & 23 & 0 & 4 & - & Pruritic rash, decreased taste sensation, leucopenia \\
8 & Female & 32 & 5 & 2 & + & Pruritic rash \\
\hline
\end{tabular}

*Impossible to evaluate because penicillamine was discontinued. 


\section{Discussion}

In the last decade studies on the antibodies to cellular (nuclear and cytoplasmic) antigens have provided additional diagnostic, prognostic, and pathogenetic clues for the autoimmune rheumatic diseases. ${ }^{17}$ Our study showed that Greek RA patients have a higher incidence of antibodies to Ro(SSA) cellular antigen compared with that of other RA patient groups tested by the same method. ${ }^{211}$

The high incidence of antibodies to Ro(SSA) cellular antigen in Greek RA patients points towards two possibilities: either Greek anti-Ro(SSA) positive RA patients possess a genetic make up which predisposes them to develop this clinicoserological picture or the environmental factor which triggers this subset of RA is more common in Greece.

Alexander et al. ${ }^{9}$ linked the presence of antiRo(SSA) with the development of Sjögren's syndrome, but no comment was made about the other differences between the anti-Ro(SSA) positive and anti-Ro(SSA) negative RA patients. We have also found an association with Sjögren's syndrome, but in this study anti-Ro(SSA) positive RA patients also differ in other aspects. The important observation made in this study was that anti-Ro(SSA) positive RA patients constitute a different clinicoserological group of RA patients who cannot tolerate Dpenicillamine treatment. These patients, as compared with anti-Ro(SSA) negative RA patients, are predominantly females with similar clinical and radiological erosive arthritis but a higher incidence of the histological features of Sjögren's syndrome. Furthermore, rheumatoid factor titres are lower than in anti-Ro(SSA) negative RA patients. It appears that anti-Ro(SSA) positive RA patients have features which overlap with SS. SS predominantly affects females who more commonly have antibodies to Ro(SSA) antigen. ${ }^{18} 19$ Females with SS have a high incidence of the alloantigen HLADR $3,{ }^{20}$ while RA is associated with HLA-DR4. ${ }^{21}$ We speculate that anti-Ro(SSA) positive RA patients have a combination of the genetic factors characterising these individual diseases.

Our observation that the antibody to Ro(SSA) is a marker for penicillamine intolerance in RA patients supplements the observation of Panayi et al., ${ }^{22}$ that RA patients with the HLA-DR3 alloantigen have a greater risk of developing Dpenicillamine side effects. A strong association between the anti-Ro(SSA) and HLA-DR3 has been previously demonstrated. ${ }^{23}$ Prospective immunogenetic studies on anti-Ro(SSA) positive and antiRo(SSA) negative RA patient groups are now under way to confirm this association. Why anti-Ro(SSA) positive RA patients and DR3 RA patients develop $\overrightarrow{\vec{F}}$ penicillamine side effects is a very intriguing $\stackrel{5}{?}$ question. Penicillamine controls RA inflammation? possibly by suppressing T lymphocyte function. ${ }^{24} 25$ 흘 It can be postulated that penicillamine-induced $\frac{\bar{\rho}}{\sigma}$ immunosuppression in RA patients with more $\stackrel{\mathbb{Q}}{\varrho}$ aggressive autoimmune disease (lymphocytic infil- ڤ tration of the exocrine glands, anti-Ro(SSA) antibody, leucopenia, etc.) further distorts the already. aberrant immunoregulation of these patients, result- $\vec{\omega}$ ing in additional immunological side effects, such as skin rashes, fever, and proteinuria.

We thank Ms E Papanikolaou and Mrs J Wright for excellent secretarial assistance.

\section{References}

1 Alspaugh M A, Maddison P J. Resolution of the identity of certain antigen antibody systems in systemic lupus erythemato- $\rightarrow$ sus and Sjögren's syndrome: an interlaboratory collaboration.음 Arthritis Rheum 1979; 22: 796-8.

2 Alspaugh M A, Talal N, Tan E M. Differentiation and $\vec{\theta}$ characterization of autoantibodies and their antigens in Sjögren's syndrome. Arthritis Rheum 1976; 19: 216-22.

3 Kassan S S, Akizuki M, Steinberg A D, Chused T M. Antibody $\square$ to a soluble acidic nuclear antigen in Sjögren's syndrome. Am JO Med 1977; 63: 328-35.

4 Martinez-Lavin M, Vaugham J H, Tan E M. Autoantibodies $\bar{\partial}$ and the spectrum of Sjögren's syndrome. Ann Intern Med 1969:ص 91: $185-90$.

5 Clark G, Reichlin M, Tomasi T B. Characterization of a soluble cytoplasmic antigen reactive with sera from patients with $\overrightarrow{\vec{O}}$ systemic lupus erythematosus. J Immunol 1969; 102: 117-22. 3

6 Maddison P J, Provost T T, Reichlin M. Serological findings in $\overrightarrow{ }$ patients with 'ANA-negative' systemic lupus erythematosus $\frac{\overrightarrow{0}}{0}$ Medicine (Baltimore) 1981; 60: 87-94.

7 Sontheimer R D, Stasny P, Maddison P J. Immunological and HLA associations in subacute lupus erythematosus [Abstract]. Clin Res 1980; 28: 582.

8 Moutsopoulos H M, Klippel J H, Pavlidis N, et al. Correlative histologic and serologic findings in sicca syndrome in patients with systemic lupus erythematosus. Arthritis Rheum 1980; 23: 36-40.

9 Alexander E L, Hirsch T J, Arnett F C, Provost T T, Stevens음 M B. Ro(SSA) and $\mathrm{La}(\mathrm{SSB})$ antibodies in the clinical spectrum of Sjögren's syndrome. J Rheumatol 1982; 9: 239-46.

10 Maddison P J, Mogavero H, Provost T T, Reichlin M. The clinical significance of autoantibodies to a soluble cytoplasmic N antigen in systemic lupus erythematosus and other tissuediseases. J Rheumatol 1979; 6: 189-95.

11 Moutsopoulos H M, Giotaki H, Maddison P J, Mavridis A K, N Drosos A A, Skopouli F N. Antibodies to cellular antigens in $\omega$ Greek patients with autoimmune diseases: anti-Ro(SSA) antibody a possible marker of D-penicillamine intolerance. Anno Rheum Dis 1984; 43: 285-7.

12 Ropes M W, Bennett G A, Cobb S, Jacox R, Jessar R. 1959 @ revision of diagnostic criteria for rheumatoid arthritis. Bull Rheum Dis 1958; 9: 175-6.

13 Reichlin $M$ and Maddison P J. Soluble tissue autoantigens which precipitate with sera of patients with connective tissue disease. In: Beutner E H, ed. Immunopathology of the skin. New York: Wiley, 1979: 357-62.

14 Comstock G W, Tockman M S, Helsing K J, Henesy K M Standardized respiratory questionnaire: comparison of the old $O$ with the new. Am Rev Respir Dis 1979: 119: 45-54. 
15 A De Carvatho. Discriminative power of Larsen's grading system for assessing the course of rheumatoid arthritis. Acta Radiol [Diagn] (Stockh) 1981; 22: 77-80.

16 Tarpley T M, Anderson L G, White C L. Minor salivary gland involvement in Sjögren's syndrome. Oral Surg 1974; 37: 64-74.

17 Tan E M. Autoantibodies to nuclear antigens (ANA). Their immunobiology and medicine. Adv Immunol 1982; 33: 167240.

18 Wasicek C A, Reichlin M. Clinical and serological differences between systemic lupus erythematosus patients with antibodies to Ro versus patients with antibodies to Ro and La. J Clin Invest 1981; 69: 835-43.

19 Moutsopoulos H M. Sjögren's syndrome current issues. Ann Intern Med 1980; 92: 212-26.

20 Moutsopoulos H M, Mann D L, Johnson A H, Chused T M. Genetic differences between primary and secondary sicca syndrome. $N$ Engl J Med 1979; 30: 761-3.
21 Stastny P. Association of the B-cell alloantigen DRw4 with rheumatoid arthritis. $N$ Engl $J$ Med 1978; 29: 869-71.

22 Panayi G S, Wooley P, Batchelor J R. Genetic basis of rheumatoid disease. HLA antigens, disease manifestations and toxic reactions to drugs. $\mathrm{Br}$ Med $J$ 1978; ii: $1326-8$.

23 Bell D A, Maddison P J. Serologic subsets in SLE: an examination of autoantibodies in relationship to clinical features of disease and HLA antigens. Arthritis Rheum 1980; 25: 1268-74.

24 Lipsky P E, Ziff M. The effect of D-penicillamine on mitogeninduced human lymphocyte proliferation: synergistic inhibition by D-penicillamine and copper salts. J Immunol 1978; 120: 1006-13.

25 Lipsky P E, Ziff M. Inhibition of human helper T-cell function in vitro by D-penicillamine and $\mathrm{CuSO}_{4}$. J Clin Invest 1980; 65: $1069-76$. 